\title{
Home Visitation Effectiveness on Students' Academic Performance During COVID-19 Pandemic
}

\author{
Gerald T. Malabarbas ${ }^{1 *}$, Gerardo L. Garcio $\mathrm{Jr}^{2}$, Priscilla G. Taperla ${ }^{2}$, Bartolome L. Amoto ${ }^{3}$ \\ 1. College of Teacher Education, University of Antique, Sibalom, Antique, Philippines \\ 2. San Joaquin National High School, San Joaquin, Calbayog City, Philippines \\ 3. Christ the King College, Calbayog City, Philippines \\ *Corresponding Author: gerald.malabarbas@antiquespride.edu.ph
}

\begin{abstract}
Due to the COVID-19 pandemic, traditional classroom instruction is being displaced with online learning. So the students are learning alone, without their parents or elders. Like home visits, schools undertake interventions to ensure that students continue to study and receive a quality education. This study on the effectiveness of the home visitation program on the academic performance of grade seven students during the COVID-19 pandemic. The study revealed that the majority of students were thirteen years old, male, their parents' occupations were fishing and farming, and with four siblings in the family. They have just a satisfactory academic performance across the different learning areas. However, there were problems encountered that have been identified by the parents and students in the implementation of home visitation such as the poor attitude and motivation towards studies of the learners, poor foundation skills, and family-related problems. The students and parents both agreed on the level of effectiveness of the home visitation intervention program. Lastly, the study disclosed that there was no statistically significant difference in perceptions of the effectiveness of the home visitation intervention program between students and their parents.
\end{abstract}

Keywords: distance learning, home visitation, Challenge

DOI: $10.7176 / \mathrm{JEP} / 13-5-07$

Publication date: February $28^{\text {th }} 2022$

\section{Introduction}

Due to the occurrence of the COVID-19 pandemic, most academic institutions are forced to resort their teaching and learning activities to flexible learning modalities through modular approach while others are on online learning modality. This shift of teaching-learning scheme happens because of the schools' closure due to lockdowns for almost more than a year since last year of March due to health crisis caused by COVID-19 as ordered by the national government and Department of Education.

Based on the report of UNESCO (2020), most countries around the world have temporarily closed educational institutions to contain the spread of the COVID-19 pandemic and reduce infections. This closure has affected more than 1.2 billion learners worldwide, with more than 28 million learners in the Philippines. Responses like community lockdown and community quarantine of several countries have led students and teachers to study and work from home, which led to the delivery of online learning platforms (Crawford et al., 2020). In the recent paper of Tria (2020), he stressed that the education sector is highly affected by the COVID-19 pandemic that includes the Philippines, wherein there are still growing COVID-19 infections. The Philippine educational sector had implemented and presented some of the new normal situations in the school setting. However, there were some posed challenges and issues presented while recommending several approaches to the new normal. Therefore, schools at all levels need to address these concerns and carefully evaluate plans and procedures to implement the new normal.

Apparently, the Department of Education (DepEd) will be implementing the Learning Continuity Plan (LCP), which will be in effect School Year 2020-2021, and classes will open on August 24, 2020, instead of June 2020 as per DepEd Order No. 018, s. 2020. Furthermore, DepEd emphasized that it would not necessarily mean that teachers and learners will go to schools and learn inside the classrooms and devised various modalities to ensure that online learning is a choice among all others in this new learning environment (DepEd, 2020).

In this scenario, the San Joaquin National High School has implemented the order and mandate of the national government and DepED that schools should set-forth flexible learning options and alternative delivery modes that would respond to the need, context, circumstances, and diversity of learners. Aside from implementing those learning modalities, the school had launched the weekly home visitation program for every learner in their respective barangays beginning the first month of classes. In order that home visitation will be the most effective one, the researchers had considered first some of the major reasons as the primary basis in conducting home visitation to one particular class section, which is the Grade 7 section Didicas. This class was chosen by the researchers as the main focus in the conduct of home visitation because of their poor academic performance in most learning areas during the first quarter; then the geographical location of the learners wherein most of them from this section are residing from this village which can be easy to visit them and the poor to the middle 
socioeconomic status of the learners which can also influence to their academic performance.

The study of Ilhan, Ozfidan, and Yilamz (2019) concluded that home visits or visitation greatly influence students' academic achievement and the relationship between teachers and students. Similarly, home visits have been found to greatly influence students' academic achievement and the relationship between teachers and students (Meyer \& Mann, 2006; Simington, 2003). Lin and Bates (2010) stated that home visits are an excellent opportunity for teachers to learn about their students' diverse backgrounds first-hand while bridging the gap between school and home.

In this light, the researchers assessed the effectiveness of the home visitation to Grade 7-Mt. Didicas students of San Joaquin National High School, Brgy. San Joaquin, Calbayog City, Samar. This primary determines how this school intervention may affect the students' academic performances, specifically on this new normal education through flexible learning modalities due to the COVID-19 pandemic.

\section{Objectives of the Study}

The study aimed to assess the effectiveness of the home visitation to the academic performance of Grade 7 - Mt. Didicas. Specifically, it sought to answer the following specific objectives: (1) Describe the profile of the students; (2) Assess the students' academic performances in all learning areas; (3) Determine the level of effectiveness of the home visitation intervention program as perceived by the students and parents; (4) Determine the significant difference on the effectiveness of home visitation as perceived by the students and their parents.

\section{Methodology}

\section{A. Research Design}

The researchers employed mixed-method research using the explanatory-sequential design. An explanatorysequential approach is a sequential approach when the researcher is interested in following up the quantitative results with qualitative data. Thus, the qualitative data is used to interpret and clarify the results from the quantitative data analysis (Edmonds and Kennedy, 2017). This study is an explanatory-sequential design or approach because quantitative data such as the profile of the learners and their perceived effectiveness of the home visitation will be assessed through the Likert scale. Findings will be further explained and sequenced with the qualitative strand of data through the in-depth interview coming from the chosen participants.

More so, the researcher adopted the research design of Ilhan, Ozfidan, and Yilmaz (2019). Figure 1 shows the paradigm of the research design of the study.

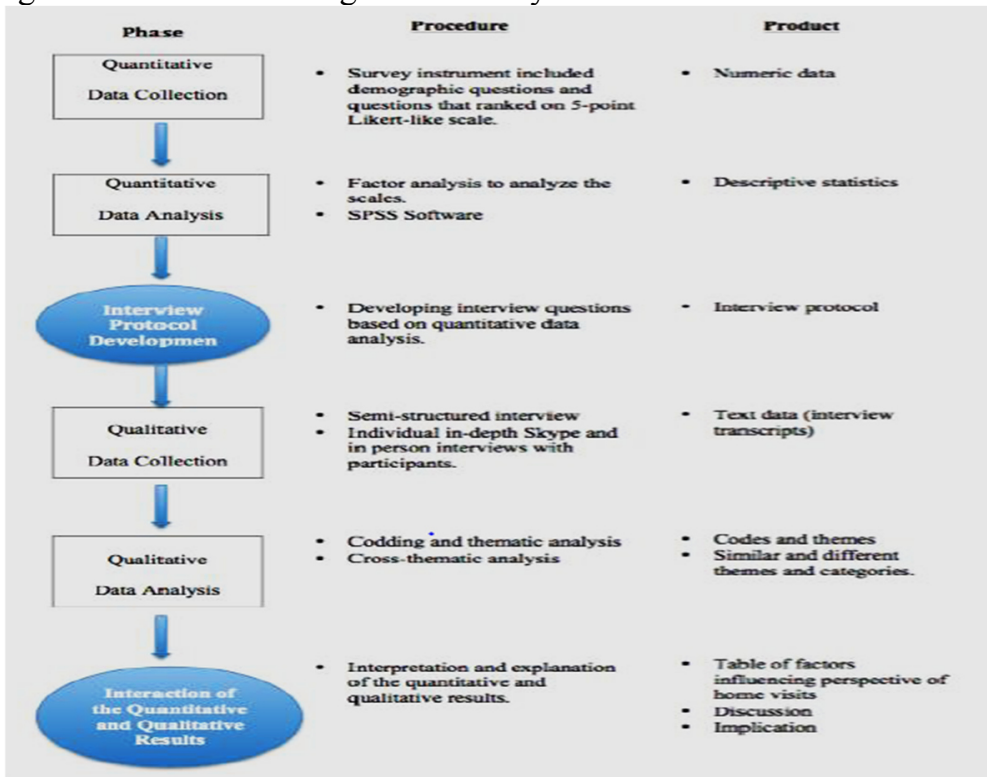

Figure 1. Adopted Research Design of the Study

\section{B. Participants of the Study}

The respondents or participants of the study were the Grade 7-Didicas students and their parents, and all of them are from Brgy. Cagnipa, while the other one is from Brgy. Danao 2. Generally, there were twenty-eight (28) students under this section who served as the study participants and their parents. This section was considered the last section of the Grade 7 level of San Joaquin National High School. Thus, there will be two (2) groups of respondents involved in this study. 


\section{Sampling Procedure}

Since this study is mixed-method research using an explanatory-sequential approach; therefore, two (2) sampling techniques were employed. For the quantitative aspect of the study, complete or total enumeration was used because both students and their parents have requested to answer the survey questionnaires. On the other hand, the convenience and quota sampling technique was used for the study's qualitative aspect through in-depth interviews. Convenience sampling is a sampling technique that qualitative researchers use to recruit easily accessible and convenient participants to the researcher. Often this may include utilizing geographic location and resources that make participant recruitment convenient (Taheredoost, 2016). Since there were ten (10) to fifteen (15) for both students and parents who participated in the in-depth interview, quota sampling will also be employed. Quota sampling is a non-random sampling technique in which participants are chosen based on predetermined characteristics so that the total sample will have the same distribution of characteristics as the wider population (Davis, 2005).

\section{Data Collection}

In gathering data, survey questionnaires were personally administered by the researchers to both students and parents. This was done during the home visitation as scheduled by the researchers after the agreement or consent has been made between the respondents and researchers. As to the respondents' profile, the researcher made use of the class School Form 1, grade sheets, and some were asked through the survey questionnaire.

Moreover, the researcher will also conduct an in-depth interview with the respondents using the interview guide questionnaire. On the other hand, data collection for the qualitative aspect of the study will be done through the in-depth interview of ten to fifteen participants. The interview was done after all the agreements has been made between the respondents and researcher. When the researchers met the data saturation during the interview, they stopped the interview and proceed to the analysis of the gathered data. According to Morse (2015), data saturation relates to the degree to which new data repeat what was expressed in previous data.

\section{E. Instrumentation}

In this study, four (4) research tools or instruments were used, such as the self-assessment checklist (SAC) for learners, parents' learning support checklist, survey questionnaire on the effectiveness of home visitation, and interview guide questionnaire.

The self-assessment checklist (SAC) for learners and parents' learning support checklist is the standard checklists used by the teachers in implementing the flexible learning modalities as required by the Department of Education. Therefore, there is no need for the validation of these instruments. On the other hand, a survey questionnaire that was used to assess the effectiveness of home visitation during this pandemic time is an adopted tool from Ilhan, Ozfidan, and Yilmaz (2019). Based on their study, the instrument's reliability value is 0.923 using Cronbach's alpha analysis, which was considered a very good tool for the study. So with this premise, the researcher will be using the said tool for this study. However, they conducted a validity and reliability test of the said instrument for fit-to-goodness use of this tool in this present study. The researchers asked fifteen respondents for both students and parents from other Grade 7 sections to answer the questionnaire. Then, they computed for reliability value of the tool using Cronbach's alpha analysis. According to Kaiser (1974), a value higher than .5 is acceptable. He also indicated that "values between 0.5 and 0.7 should be considered mediocre, values between 0.7 and 0.8 should be considered good, values between 0.8 and 0.9 should be considered great, and values of more than 0.9 should be considered superb" (Anderson \& Gerbing, 1984). Further, the survey questionnaire contains thirteen (13) statements or indicators that measured the effectiveness of home visitation using the five-point Likert scale as follows: " 1 = Strongly Disagree, 2 = Disagree, $3=$ Neutral, 4 = Agree, and $5=$ Strongly Agree."

\section{F. Data Analysis}

The researchers have tallied and treated the gathered data using the Statistical Package for Social Sciences (SPSS) software. The following statistical tools were used to analyze and interpret the data:

Frequency and percentage distribution were employed to describe Grade 7 - Mt. Didicas students' profiles regarding their age, sex, parent's occupation, number of siblings, and family monthly income. Likewise, the mean and standard deviation were also employed to describe the age, the number of siblings, and family monthly of the respondents; hence these are ratio variables. Likewise, the mean and standard deviation were used to describe the students' academic performances across different learning areas such as English, Science, Mathematics, Filipino, Araling Panlipunan, TLE, and Edukasyon sa Pagpapakatao from first to third quarters perceived responses of the students based on the self-assessment checklist (SAC) for learners, perceived responses of the parents based on the parent's learning support checklist, and the level of effectiveness of the home visitation intervention program as perceived by both the students and parents. Then, the Kruskal-Wallis test was used to measure the significant difference between the students' and their parents' perceptions on the effectiveness of the home visitation intervention program. 


\section{Results and Discussions}

\section{Profile of the Grade 7 - Mt. Didicas Students}

As can be gleaned from Table 2, the age of the Grade 7 - Mt. Didicas ranges from 12 years old to 17 years old with a mean age of 13.29 years old and standard deviation of 1.12. This means that most of the students are at the right age of their grade level although some are aged older than their present grade level. In terms of sex, the majority of the students are more males (17 or $60.7 \%$ ) as compared to females (11 or 39.3\%). This suggests that the class of Grade 7 - Mt. Didicas is dominated by male students rather than female students.

As to the parent's occupation of the students, fishing (12 or 42.9\%) is the most frequent occupation, followed by farming ( 9 or $32.1 \%$ ), while others are having sari-sari store ( 3 or $10.7 \%$ ), vendor/selling $(2$ or $7.1 \%)$ and construction worker $(2$ or $7.1 \%)$. The data disclose that it is really evident that the source of living of the parents are fishing and farming that justified that they are living in the coastal communities where the people the major source of occupation are fishing in their nearby sea and farming in their farms tilling the lands and planting a variety of agricultural crops as their source of food and income.

Lastly, in terms of the number of siblings, the respondents have 2 to 9 siblings in the family. Most of them have 4 (10 or $35.7 \%$ ) siblings, followed by 5 ( 7 or $25.0 \%$ ), and 3 (6 or $21.4 \%$ ). While, some of them have 6,8 , or 9 siblings already. However, the mean value of the number of siblings is 4.00 with a standard deviation of 3.65. This implies that most of the respondents belong to a medium family size although others have a bigger size of family members.

Table 2. Frequency and Percentage Distribution on Profile of the Grade 7 - Mt. Didicas Students $(n=28)$

\begin{tabular}{lcc}
\hline \hline Profile Variables & Frequency (f) & Percentage (\%) \\
\hline Age (in years old) & 6 & 21.4 \\
12 & 13 & 46.4 \\
13 & 6 & 21.4 \\
14 & 2 & 7.1 \\
15 & 1 & 3.6 \\
17 & & \\
$\bar{x}=13.29 ;$ sd=1.12 & & \\
Sex & 17 & 60.7 \\
Male & 11 & 39.3 \\
Female & & \\
Parent's Occupation & 9 & 32.1 \\
Farming & 12 & 42.9 \\
Fishing & 2 & 7.1 \\
Vendor/Selling & 3 & 10.7 \\
Sari-sari Store & 2 & 7.1 \\
Construction Worker & & \\
Number of Siblings & 2 & 7.1 \\
2 & 6 & 21.4 \\
3 & 10 & 35.7 \\
4 & 7 & 25.0 \\
5 & 1 & 3.6 \\
6 & 1 & 3.6 \\
8 & & 3.6 \\
9 & & \\
$\bar{x}=4.00 ;$ sd=3.65 & & \\
\hline \hline
\end{tabular}

Grade 7- Mt. Didicas Students' Academic Performances in All Learning Areas

Table 3 disclosed the academic performance of Grade 7-Mt. Didicas in all learning areas from the first quarter to the fourth quarter. As can be gleaned from the table, the academic performance of the students during the first quarter across the different learning areas are mostly "fairly satisfactory", except only for Science and Filipino which the students performed "satisfactorily". During the second quarter, the students performed "satisfactory" in all subject learning areas. The same performance was continually shown by the students during the third quarter, except only for EsP that the students where their performance leveled up to "very satisfactory". Moreover, during the fourth quarter, the performance of the peaked at "Very Satisfactory" in English, Science, Araling Panlipunan, MAPEH, TLE, and Edukasyon sa Pagpapakatao, while, they showed "satisfactory" performance in Mathematics and Filipino. 
Table 3. Academic Performances of Grade 7 - Mt. Didicas in All Learning Areas

\begin{tabular}{|c|c|c|c|c|c|c|c|c|c|c|c|}
\hline \multirow{2}{*}{$\begin{array}{c}\text { Subject } \\
\text { Learning } \\
\text { Areas }\end{array}$} & \multicolumn{8}{|c|}{$\begin{array}{c}\text { Quarterly Mean } \\
\text { Performances }\end{array}$} & \multirow{2}{*}{$\begin{array}{c}\text { Over-all } \\
\text { Performance }\end{array}$} & \multirow{2}{*}{$\begin{array}{l}\text { Standard } \\
\text { Deviation }\end{array}$} & \multirow[b]{2}{*}{ Descriptor } \\
\hline & $1^{\text {st }}$ & PD & $2^{\text {nd }}$ & PD & $3^{\text {rd }}$ & PD & $4^{\text {th }}$ & PD & & & \\
\hline English & 76.29 & FS & 80.68 & $\mathrm{~S}$ & 82.32 & $\mathrm{~S}$ & 85.18 & VS & 81.12 & 1.237 & Satisfactory \\
\hline Science & 80.54 & S & 81.64 & S & 82.68 & $\mathrm{~S}$ & 85.86 & VS & 82.68 & 1.984 & Satisfactory \\
\hline Math & 79.71 & FS & 81.86 & S & 82.68 & S & 83.79 & $\mathrm{~S}$ & 82.01 & 1.905 & Satisfactory \\
\hline Filipino & 81.04 & S & 81.25 & $\mathrm{~S}$ & 82.75 & $\mathrm{~S}$ & 84.79 & $\mathrm{~S}$ & 82.46 & 1.244 & Satisfactory \\
\hline Aral Pan & 79.36 & FS & 81.57 & S & 82.93 & $\mathrm{~S}$ & 85.75 & VS & 81.40 & 4.102 & Satisfactory \\
\hline MAPEH & 79.57 & FS & 81.36 & S & 83.61 & S & 86.18 & VS & 82.68 & 1.921 & Satisfactory \\
\hline TLE & 78.43 & FS & 81.11 & S & 83.54 & $\mathrm{~S}$ & 86.07 & VS & 82.29 & 1.750 & Satisfactory \\
\hline EsP & 79.29 & FS & 81.00 & S & 85.29 & VS & 86.43 & VS & 83.00 & 3.752 & Satisfactory \\
\hline Average & 79.28 & FS & 81.31 & $\mathbf{S}$ & 83.22 & $\mathbf{S}$ & 85.51 & VS & 82.21 & 1.186 & Satisfactory \\
\hline
\end{tabular}

Legend:

Numerical Grade
$90-100$
$85-89$
$80-84$
$75-79$
Below 75

\author{
Performance Descriptor (PD) \\ Outstanding $(\mathrm{O})$ \\ Very Satisfactory (VS) \\ Satisfactory (S) \\ Fairly Satisfactory (FS) \\ Did Not Meet Expectations (DME)
}

Below 75

Although the overall performance of the students is "satisfactory" on the other hand, tracing the academic performance of the Grade 7-Mt. Didicas students increased and got better from the first quarter to the last quarter across the eight subject learning areas. The data show that the intervention given to the students is effective because it is apparent in their good academic performance that despite the learning modality of the students being modular still perform better with their respective subject learning areas and this made possible to them through this home visitation as intervention program given to the Grade 7-Mt. Didicas students.

Further, during the interview with the parents of the students, they eventually observed that the academic performance of their children had really improved because according to them with this intensive home visitation made by the teachers, the learners (their children) were able to easily recall their prior knowledge in connection with the lessons and topics, they have gained new skills during the teaching and learning process especially when the one-on-one session with the teacher and the student, through this intervention the students have boosted their confidence and creativity in making their learning tasks (e.g projects, artworks), and most importantly the slow learners were given the opportunity to established and developed their new skills especially in reading and arithmetic that made their children learn independently.

Problems Encountered by the Students and Parents during the Implementation of Home Visitation

After the series of interviews with the students, parents, and teachers, the researcher got three (3) themes on the problem encountered during the implementation of home visitation, as follows:

Student Attitude and Motivation. Students sometimes got shy when their teachers went to their house for the conduct of the home visitation. Due to this attitude, it causes to delimits their interaction with the teacher during the tutorial or one-on-one session. Others are hesitant to face their teachers as they arrived in their homes. While some of the students have a lack of interest and motivation in attending their sessions with the teachers. Some of them lack sleep and have overdue activities due to online games and paying attention to social media such as Youtube, Facebook, Twitter, and the likes.

Poor Foundation Skills. Since this is Grade 7 the entry-level of the students to junior high school, they found difficulty in learning some Grade 7 subject learning areas like Mathematics and subjects that need comprehension. It was found out that some students lack the skill in reading and comprehension. With this, the students find it hard in answering their learning activity sheets and in making outputs. It was also observed that some students lack a solid foundation in the fundamental operations in Mathematics.

Family Related Problems. Some students have low interest and got late in facing teachers during the home visitation and one-on-one session because of the household chores they need to attend to. Some are sent to do an errand, household chores, babysitting, while others are helping their parents in their livelihood like fishing and farming. With this meager family income, the students have difficulty in making their projects and materials due to a lack of financial support. Some parents cannot make a follow-up to their children because they are busy with their livelihood and works to be attended to. Moreso, there are some parents/guardians who were not present during the visitation because of their work. 
Level of Effectiveness of the Home Visitation Intervention Program as Perceived by Students and Parents As can be seen from Table 4 both the students and parents perceived that the home visitation intervention program is generally effective as shown on their unanimous perceived responses wherein all the indicators have uniformly responded by both students and parents as "agreed" since all the mean values range between 3.40 to 4.19 with a standard deviation of less than 0.5 which indicates that the responses of students and parents are almost closed perception to one another as to their agreement on the different indicators given in the survey tool. This only means the home visitation intervention program significantly helps the students in their modular learning at home and improves their academic performance despite being on the precipice of the pandemic.

Table 4. Mean and Standard Deviation on the Level of Effectiveness of the Home Visitation Intervention Program as Perceived by Students and Parents

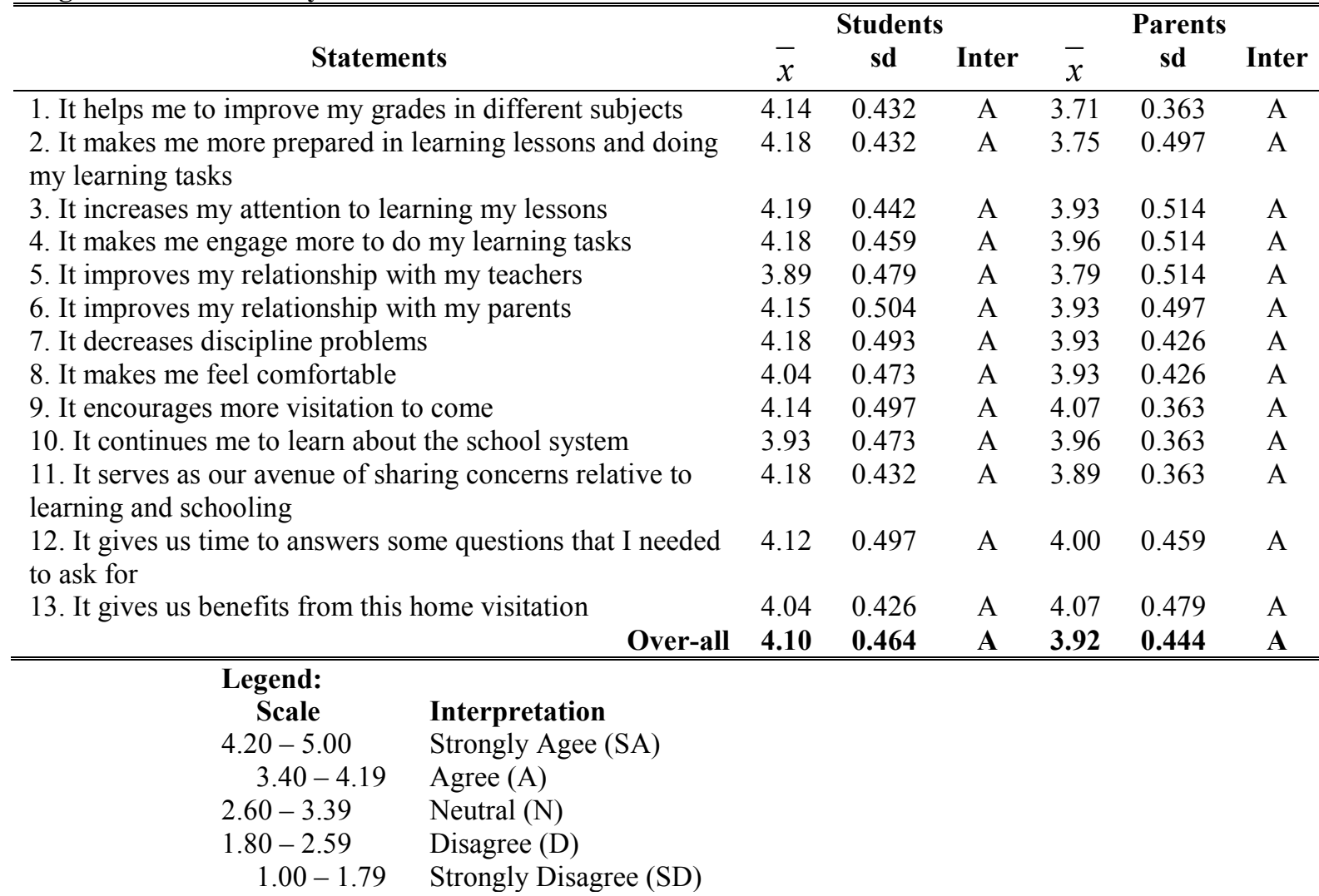

Concomitantly, based on the in-depth interview results revealed that all parents have consistently agreed that the home visitation intervention program is effective. According to the parents, their children learned so much from every one-on-one session of the teachers and students during home visitation. As they openly gave their feedbacks that teachers gave additional information about the topic being discussed in the LAS, teachers clarified the activities in the module, elaborate the thoughts presented in the learners' activity sheets, simplified the complicated concepts in the LAS like giving the step by step ways in solving Mathematical equations as well to other subjects and the teachers give detailed concepts about the discussions within the LAS. Moreover, the learners grasp the ideas being presented in the LAS and interacted accordingly to the discussion of the teacher during the visitation. With this, parents witnessed that the learners' activity sheets showed improved scores and even themselves learned many things during the home visitation made by the teachers.

Test of Difference on the Perception of the Home Visitation Intervention Program's Effectiveness Between the Students and their Parents

Table 5. Tests of Normality of the Data

\begin{tabular}{llcccccc}
\hline \hline & & \multicolumn{3}{c}{ Kolmogorov-Smirnov $^{\mathrm{a}}$} & \multicolumn{3}{c}{ Shapiro-Wilk } \\
\cline { 3 - 8 } Label & & Statistic & $\mathrm{df}$ & Sig. & Statistic & $\mathrm{df}$ & Sig. \\
\hline Effect & Student & .113 & 28 & $.200^{*}$ & .963 & 28 & .420 \\
& Parent & .214 & 28 & .002 & .888 & 28 & .006 \\
\hline \hline
\end{tabular}

*. This is a lower bound of the true significance.

a. Lilliefors Significance Correction

The normality of effectiveness as perceived by students and parents was assessed. The Shapiro-Wilk test 
indicated that the score was not normally distributed, as reflected in Table 4 and as it showed with the statistical values of $d f(28)=0.963, p$-value $=.420$ and $d f(28)=0.888, p$-value $=.006$, respectively, where one of the $\mathrm{p}$ values is greater than 0.05 .

Thus, the most appropriate test of significant difference on the perception of the respondents is Mann-Whitney U Test, a non-parametric test statistic.

Table 6. Test for Significant Difference between the Perception of the Home Visitation Intervention Program's Effectiveness between the Students and their Parents

\begin{tabular}{lrrrcc}
\hline & $\mathrm{N}$ & Mean Rank & Sum of Ranks & Statistics & p-value \\
\hline Student & 28 & 32.21 & 902.00 & 288.00 & $0.09^{\text {ns }}$ \\
Parent & 28 & 24.79 & 694.00 & & \\
Total & 56 & & & & \\
\hline
\end{tabular}

A Mann-Whitney test indicated that there is no significant difference between the perception of the home visitation intervention program's effectiveness of the students and their parents, $U=288$, p-value $=.09$. This data suggests that the null hypothesis stating that there is a significant difference between the perception of the home visitation intervention program's effectiveness of the students and their parents is rejected. This can be concluded that the perception of both students and parents on the effectiveness of the home visitation intervention program is most likely the same. This test of significant difference is supported by the level of perception of the respondents on the said intervention as presented in Table 4.

\section{Conclusions and Recommendations}

\section{Conclusions}

Based on the findings of the study, the researchers concluded the following:

1. Majority of the Grade 7 - Mt. Didicas students were 13 years old, male, their parents' occupations were fishing and farming, and having four (4) siblings in the family.

2. The Grade 7- Mt. Didicas students' academic performances in all learning areas were satisfactory.

3. The problems encountered by the students and parents during the implementation of home visitation were identified as students' attitude and motivation, poor foundation skills, and family-related problems.

4. Both the students and parents have agreed with their perception on the level of effectiveness of the home visitation intervention program.

5. There was no significant difference between the perception of the students and parents on the effectiveness of the home visitation intervention program.

\section{Recommendations}

The researchers advanced the following recommendation based on the findings and conclusions of the study:

1. There will be regular and intensive conduct of the home visitation program to ensure the academic performance improvement of the students.

2. Remedial class will be given to students who have weak foundation skills for them to catch up with the high school lessons and develop the expected competencies.

3. Additional reading materials and learning support materials will be given to the students so that the learners will be motivated to work on their activities and improve their study habits.

4. Effective parenting will be conducted and given to the parents for them to be equipped on do's and don't of disciplining their children and establish a strong relationship between parents and children.

5. Symposium on time management and stress management will be given to both students and parents so that they can manage their time and stress especially during these trying times of pandemic.

6. Establish a good rapport between the parents and the teachers to facilitate the home visitation program effectively and efficiently as well as to other programs of the schools.

\section{Acknowledgment}

The researchers would like to thank the parents and students who participated in the study and to teachers who cooperated in the conduct of this study. To the school administration for the financial support.

\section{References}

Anderson, J. C., \& Gerbing, D. W. (1984). The effect of sampling error on convergence, improper solutions, and goodness of fit indices for maximum likelihood confirmatory factor analysis. Psychometrika, 49: 155-173. Retrieved February 25, 2021, http://dx.doi.org/10.1007/BF02294170.

Crawford, J., Butler-Henderson, K., Jurgen, R., Malkawi, B. H., Glowatz, M., Burton, R., Magni, P., \& Lam, S. (2020). COVID-19: 20 countries' higher education intra-period digital pedagogy responses. Journal of Applied Learning \& Teaching, 3. Retrieved February 15, 2021, https://doi.org/10.37074/jalt.2020.3.1.7 
Davis, D. (2005). Business Research for Decision Making. Thomson South-Western Publishing, Australia.

DepEd. (2020). Official Statement Department of Education. Retrieved February 15, 2021, https://www.deped.gov.ph/2020/05/06/official-statement-2.

Edmonds, W. \& Kennedy, T. (2017). Action research approaches. In An applied guide to research designs (pp. 212-217). SAGE Publications, Inc, Retrieved February 20, 2021, https://www.doi.org/10.4135/9781071802779.

Ilhan, F., Ozfidan, B., \& Yilmaz, S. (2019). Home visit effectiveness on students' classroom behavior and academic achievement. Journal of Social Studies Education Research, 10(1): 61-80.

Kaiser, H. F. (1974). An index of factorial simplicity. Psychometrika, 39: 31-36.

Lin, M., \& Bates, A. B. (2010). Home visits: How do they affect teachers' beliefs about teaching and diversity? Early Childhood Education Journal, 38(3), 179-185.

Meyer, J. A., \& Mann, M. B. (2006). Teachers' perceptions of the benefits of home visits for early elementary children. Early Childhood Education Journal, 34(1), 93-97.

Morse, J.M. (2015). Data were saturated. Qualitative Health Research, 25(5): 587-588.

Tria, J. Z. (2020). The COVID-19 Pandemic through the lens of education in the Philippines: The new normal. International Journal of Pedagogical Development and Lifelong Learning, 1(1), ep2001. Retrieved February 15, 2021, https://doi.org/10.30935/ijpdll/8311.

UNESCO. (2020). COVID-19 Educational Disruption and Response. Retrieved February 15, 2021, https://en.unesco.org/covid19/educationresponse

Zhao, Y., Guo, Y., Xiao, Y., Zhu, R., Sun, W., Huan, W., Liang, D., Zhang, F., Zhu, D., \& Wu, J. (2020). The effect of online homeschooling on children, parents, and teachers of Grade 1-9 during the COVID-19 pandemic. Clinical Research. DOI: 10.1:26591MSM.925591. 